Gut, $1965,6,140$

\title{
The pancreas and iron absorption
}

\author{
A. E. DAVIS AND J. C. BIGGS \\ From the Department of Medicine, Prince Henry Hospital, Sydney, and \\ Garvan Institute of Medical Research, St. Vincent Hospital, Sydney, \\ N.S.W., Australia
}

EDITORIAL SYNOPSIS The uptake of iron from an isolated perfused loop of rat jejunum can be inhibited by the addition of pancreatic extract. The active factor appears to be water soluble and heat labile.

Earlier work has shown that the absorption of a physiological dose of iron is increased in patients with calcific pancreatitis (Davis, 1961; Davis and Badenoch, 1962). Furthermore, iron absorption can be reduced significantly in patients with haemochromatosis (Biggs and Davis, 1963) and cirrhosis of the liver (Callender and Malpas, 1963; Davis and Biggs, 1964), by the addition of a pancreatic extract, Viokase, to the oral dose of iron. These results support the hypothesis that a pancreatic factor may play an important role in the control of iron absorption.

To investigate the site of action, chemical nature, and specificity of this factor we designed a series of experiments in rats. This paper describes the method employed and the results of the first series of tests.

\section{METHODS}

Female rats of the Wister strain weighing approximately $250 \mathrm{~g}$. were used in all experiments. They were fed on a commercial diet (supplied by D.H.A.-Rural). After an overnight fast the animals were given intraperitoneal nembutal ( $2 \mathrm{mg} . / 100 \mathrm{~g}$. of body weight) followed by ether anaesthesia. The abdomen was opened and a polythene tube was inserted into the proximal end of the jejunum. At a distance of $20 \mathrm{~cm}$. a second tube was inserted into the intestine establishing an isolated loop in situ (Fig. 1). This loop was gently washed through with about $10 \mathrm{ml}$. of saline to remove residual food debris together with biliary and pancreatic secretions, and a small amount of air was blown through the loop to empty it as completely as possible. After clamping both tubes a measured quantity of the various isotopically labelled solutions could be injected through the proximal tube into the loop. After $\mathbf{4 0}$ minutes the loop was washed through with $60 \mathrm{ml}$. of normal saline to remove the unabsorbed radioactivity. (By fractional washings it had been shown that this quantity was sufficient to remove the 'nonabsorbed' radioactivity.) The loop was removed and the animal was killed. Aliquots of the standard

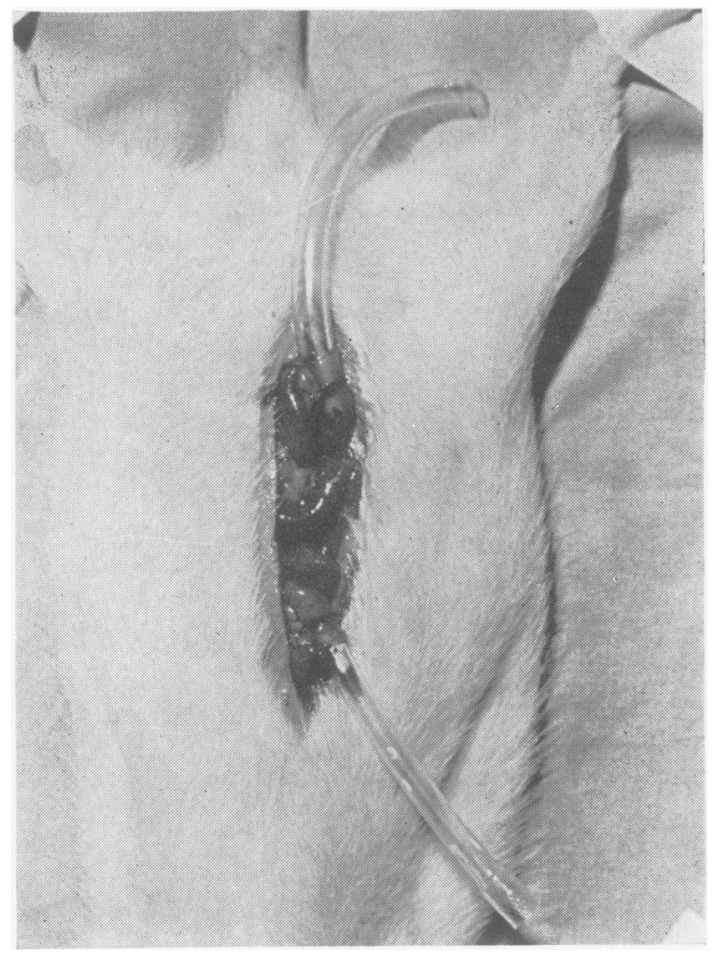

FIG. 1. The isolated loop of jejunum in the rat before clamping.

solution, washouts, and the intestinal loop were counted in plastic vials suitable for use in the E.C.K.O. well counter.

\section{PREPARATION OF IRON SOLUTION AND PANCREATIC EXTRACT}

Fresh ferrous sulphate solutions were prepared before each experiment. The solution contained $50 \mu \mathrm{g}$. of iron 
per millilitre and the dose given to all animals was $0.5 \mathrm{ml}$. $(25 \mu \mathrm{g} . \mathrm{Fe})$.

When testing the effect of pancreatic extract $0.25 \mathrm{~g}$. of the extract was added to $5 \mathrm{ml}$. of the iron solution and well shaken. After centrifugation the water-soluble supernatant was labelled with iron ${ }^{59}$. In other experiments concentrated sulphuric acid was added to reduce the $p H$. To study the effect of heat an aqueous solution of the pancreatic extract was autoclaved at $15 \mathrm{lb}$. pressure for 15 minutes. Ferrous sulphate labelled with $\mathrm{Fe}^{59}$ was added to the supernatant so that the resultant solution contained $50 \mu \mathrm{g}$. per ml.

\section{RESULTS}

When ferrous sulphate at $p \mathrm{H} 1$ was instilled into the loop the mean intestinal uptake was $50 \%$ with a range of 40 to $67 \%$ of the administered dose whereas the mean uptake in the presence of a water-soluble fraction of the pancreatic extract was $29 \%$ with a range of 12 to $44 \%$. This difference was highly significant $(\mathrm{P}<0.01$, Table $\mathrm{I})$.

When the ferrous sulphate was instilled into the loop at $p \mathrm{H} 5$ the mean intestinal uptake was $58 \%$ with a range of 31 to $81 \%$ of the administered dose;

\section{TABLE I}

PERCENTAGE UPTAKE OF $25 \mu \mathrm{g}$. FeSO $_{4}$ FROM THE ISOLATED PERFUSED SEGMENT OF RAT INTESTINE AT $p H$ 1.0 Iron Only

Iron and Pancreatic Extract

$\begin{array}{cc}51 & 35 \\ 55 & 28 \\ 41 & 26 \\ 67 & 12 \\ 40 & 29 \\ 53 & 44 \\ 45 & 33 \\ 46 & 27 \\ 62 & 39 \\ 44 & \\ 42 & \\ 48 & \\ \text { Mean } 50 & \\ & \end{array}$

TABLE II

PERCENTAGE UPTAKE OF $25 \mu$ G. FeSO $_{4}$ FROM THE ISOLATED PERFUSED SEGMENT OF RAT INTESTINE AT $p \mathrm{H}$ 5.0

$\begin{array}{lll}\text { Iron Only } & \begin{array}{l}\text { Iron }+ \text { Pancreatic } \\ \text { Extract }\end{array} & \begin{array}{l}\text { Iron }+ \text { Heated } \\ \text { Pancreatic Extract }\end{array}\end{array}$

\begin{tabular}{crr}
\hline 65 & 8 & 61 \\
72 & 5 & 35 \\
76 & 14 & 50 \\
47 & 5 & 55 \\
40 & 4 & 53 \\
61 & 7 & \\
51 & 10 & \\
64 & 11 & \\
74 & 35 & \\
81 & 25 & \\
55 & & \\
46 & & \\
31 & & \\
59 & & \\
46 & & \\
Mean 58 & Mean 12 & \\
\end{tabular}

at this $p H$ the addition of the pancreatic extract resulted in a mean uptake of $12 \%$ for the range of 4 to $35 \%$ of the administered dose. These findings were highly significant $(\mathbf{P}<0.001$, Table II).

After autoclaving the extract at $15 \mathrm{lb}$. pressure for 15 minutes the mean uptake was $51 \%$ with a range of 35 to $61 \%$ (Table II).

\section{DISCUSSION}

The above results show that in the isolated jejunal loop of a rat the uptake of iron can be inhibited by the addition of a pancreatic extract. This effect is noticed at a $p \mathrm{H} 1$ and at $p \mathrm{H} 5$ but is more marked at the latter $p \mathrm{H}$.

This inhibitory effect of a pancreatic extract on the uptake of iron from the isolated perfused segment of the intestine of the rat supports the hypothesis that pancreatic secretions play some part in the regulation of iron absorption. It has been shown that there is an increase in the absorption of iron in some patients with calcific pancreatitis (Davis, 1961; Davis and Badenoch, 1962) and in untreated patients with fibrocystic disease of the pancreas (Smith, 1964). Histological studies have lent further support: Davis in 1961 reported haemosiderosis in three out of four patients with calcification of the pancreas and a high incidence of haemosiderosis of the liver and spleen was reported in 1938 by Andersen in patients with fibrocystic disease of the pancreas.

Cirrhosis of the liver is another condition often associated with haemosiderosis (Herbut and Tamaki, 1946) and there is both histological (Woldman, Fishman, and Segal, 1959) and clinical evidence (van Goidsenhoven, Henke, Vacca, and Knight, 1963) of pancreatic involvement in this condition, and in addition the giving of a pancreatic extract before an oral dose of radioactive iron has been shown to inhibit the absorption of iron in this disease (Callender and Malpas, 1963; Davis and Biggs, 1964).

Similarly in haemochromatosis marked fibrosis of the pancreas is extremely common (Sheldon, 1935), and recently Biggs and Davis (1963) have reported that the giving of a potent pancreatic extract before an oral dose of iron reduces absorption of iron in this condition.

Bothwell stated at a recent international symposium on iron metabolism (Gross, 1964) that he has reduced by $50 \%$ the absorption of iron by the injection of secretin and pancreozymin in rats. The above evidence lends further support to the hypothesis that there is a factor in pancreatic secretions which inhibits the absorption of iron. The results reported in this paper suggest that this substance is water soluble and heat labile though it must be stressed that we have measured uptake from 
an isolated perfused loop of jejunum and not actual absorption; this we are measuring at the present time.

While it is extremely likely that there is in the pancreatic secretions a factor which inhibits the absorption of iron, its physiological importance has yet to be determined in the overall process of iron absorption and utilization. More work has yet to be carried out to determine whether this effect is limited to pancreatic secretions or whether other secretions of the gastrointestinal tract play a part in the intraluminal phase of the absorption of iron.

\section{REFERENCES}

Andersen, D. H. (1938). Cystic fibrosis of the pancreas and its relation to celiac disease. Amer. J. Dis. Child., 56, 344-399.
Biggs, J. C., and Davis, A. E. (1963). Relationship of diminished pancreatic secretion to haemochromatosis. Lancet, 2, 814.

Callender, S. T., and Malpas, J. S. (1963). Absorption of iron in cirrhosis of liver. Brit, med. J., 2, 1516-1518.

Davis, A. E. (1961). Relationship of disturbed pancreatic function to haemosiderosis. Lancet, 2, 749-750.

$\longrightarrow$, and Badenoch, J. (1962). Iron absorption in pancreatic disease. Ibid., 2, 6-8.

-, and Biggs, J. C. (1964). Iron absorption in haemochromatosis and cirrhosis of the liver. Aust. Ann. Med., 13, 201-203

Gross, F. (1964). Iron Metabolism. Springer-Verlag, Berlin.

Herbut, P. A., and Tamaki, H. T. (1946). Cirrhosis of the liver and diabetes as related to hemochromatosis. Amer. J. clin. Path., 16, 640-650.

Sheldon, J. H. (1935). Haemochromatosis. Oxford University Press, London.

Smith, R. S. (1964). Iron absorption in cystic fibrosis. Brit. med. J., 1, 608-609.

Van Goidsenhoven, G. E., Henke, W. J., Vacca, J. B., and Knight, W. A., Jr. (1963). Pancreatic function in cirrhosis of the liver. Amer. J. dig. Dis., 8, 160-173.

Woldman, E. E., Fishman, D., and Segal, A. J. (1959). Relation of fibrosis of the pancreas to fatty liver and/or cirrhosis. J. Amer. med. Ass., 169, 1281-1283. 